\title{
Economic and Managerial Problems in the Field of Culture
}

\author{
Nataliya Malshina \\ Saratov State Conservatory Named after L. V. Sobinov, \\ Research Institute of Goods Circulation and Wholesale Market Conjuncture \\ Moscow, Russia \\ E-mail: malsnataliya@yandex.ru
}

\begin{abstract}
The article presents the methodology of realization of the public-private partnership mechanism in cultural industry, balanced in terms of the correlation between risks and responsibility. This mechanism will allow to reduce costs, ensure investment and lower the risk level in the industry of culture, thus determining its attractiveness and competitiveness. The objective of the article consists in elaborating the instruments of public-private partnership in cultural industries, which can take legal, organizational and financial forms, having as models methodological, organizational, resource, legislative and motivational support. The directions of the use of public-private partnership are quite multilateral: they include government and political support, organizational-economic and investment-financial conditions, legislative basis and staffing. We have used the methodology of mathematical-economic modeling extended by the functional analysis of the cultural industry in the Russian Federation. The statistical method of the time series analysis of the cultural industry's official rates in 2005-2017 in different countries that has been applied in the research shows the trends from double-digit growth to double-digit fall. The calculation of the criteria weight of public-private partnership is conducted using both the method of expert evaluation and the formal method of determining weighting coefficients. The most efficient method in the theory of expert evaluation has proved to be the ranking and scoring method. Applying the scoring methods, experts evaluate the importance of a separate criterion on the scale from 0 to 10 . Formal methods of determining weighting coefficients assess the importance of separate criterion with the help of coefficients. We have managed to work out the support measures for each life cycle of the development of cultural and creative industry, and namely: financial measures - guarantee schemes and other financial and credit mechanisms, accessibility of seed and venture capital etc.; productional measures; market measures; administrative and political measures; supporting measures. The state as a part to the partnership agreement of publicprivate partnership can assume the functions of risk insurance by means of providing guarantees on state credits or subventions at different levels, export credit insurance and counter-guarantees. This mechanism will allow to reduce the costs, ensure investment and lower the risk level of cultural industries, thus determining attractiveness and competitivity of the cultural sphere. We state the fact that the use of the technologies of financing the cultural and creative industry approved by the $\mathrm{EU}$ will allow to create the mechanism of support based on the organizational, behavioral and technical
\end{abstract}

interconnections in Russia as well. Apart from direct effectiveness, the influence of culture on economic efficiency also has an indirect impact revealed in supporting the values common for customer groups which define the ways of involvement of the members of a group into the economic production processes. The results of the research may prove useful for the elaboration of government policy measures for the implementation of the forms of financing cultural and creative sphere in today's economy.

Keywords - the cultural industries in the Russian Federation; public-private partnerships; financial support

\section{INTRODUCTION}

From the beginning of the 20th century a new social and cultural significance of commercial cultural production that has become the basis of the "epoch of cultural production" has mounted in the modern society [1]. Cultural industries are a complex business structure interested in realizing profit by means of producing and distributing texts. Complex, ambivalent and controversial cultural industries have different logic which is applied in various types of cultural production - the result of the realization of the issues of the industrialization of culture and the refusal to simplify its evaluation and understanding.

The model of cultural industries consists of the "concentric circles, with art industries in its center, whereas others form their own layers and circles placed around the center and extended far away as the use of creative ideas is introduced into a larger production context" [2]. Moving away from the center, one can find the following circles:

- Cultural industries whose production is considered to be cultural goods; however, they also provide other goods and services that have no connection with culture;

- Industries that generally activate outside the cultural sphere, but their products can be described as having a certain cultural content [3].

The difficulty of defining cultural industries is caused by vague terminology of cultural goods and services. Further global integration of society, culture and business require new mechanisms of ensuring the development of cultural 
industries in the Russian Federation, and public-private partnership can become one of them.

\section{MATERIALS AND Methods (MODEL)}

In 2016 the total of paid services rendered to the population amounted to 8377,8 billion rubles, while in December 2016 - to 764,0 billion rubles. The unit weight of the costs of service payment in public customer expenditure amounted to $21.4 \%$ in 2016 , as compared to $20.7 \%$ in 2015 , and in December 2016 - to $19.5 \%$, as compared to $18.8 \%$ in December 2015. As can be seen from Figure 1, the dynamics of paid services in 2015-17 can hardly be characterized as stable and has seen rises and falls - December 2015 and January 2016.

The structure of the use of financial resources by the institutions of the Russian Ministry of Culture is traditionally dominated by labor remuneration 62380,8 million pub.; however, we have to mention the appearance of some new financing items (and namely, internal funds 2875,6 million pub.), as well as new items of application that have dramatically increased rates (and namely, socially significant activities 6083,8 million pub.) in "Fig. 1".

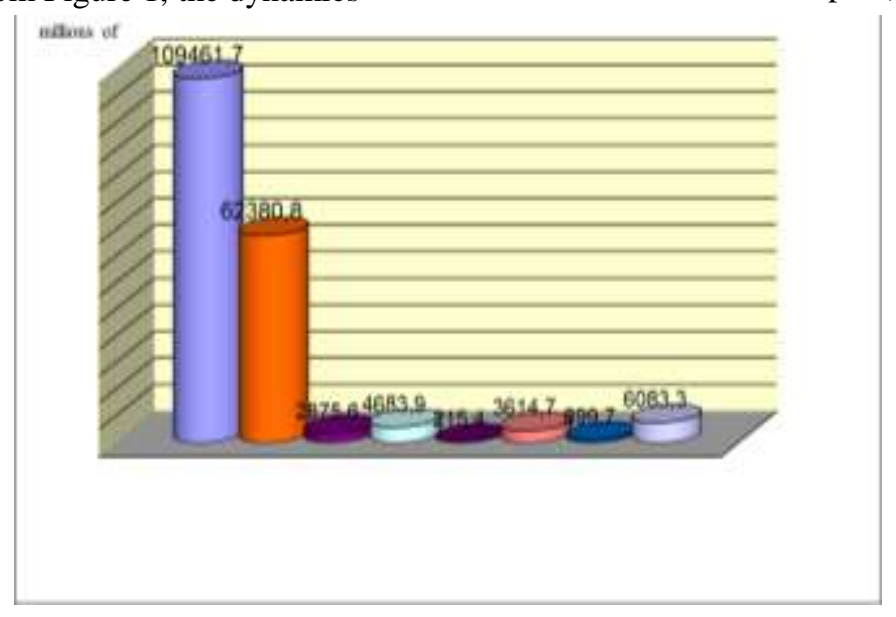

Fig. 1. Structure of the use of financial resources by the institutions of the Russian Ministry of Culture.

According to the statistical data of the United Nations Conference on Trade and Development (UNCTAD) 2017 for the year 2016, the growth rate of international trade in personal and cultural services accounted for 3\%; a higher rate is observed only in the case of trade in computer and informational services (4.5\%). In 2016 the volume of world exports reached 4.9 trillion dollars in the USA, which makes up a third of the volume of merchandise exports. Thus, global trade in services remained unchanged until past two years, after the period of sustainable growth from 2009 to 2014. In 2016 the first place in world export of services was occupied by the services in the field of intellectual property, development and research, which together amount to around 1 trillion USA dollars, while the export of tourist services held the second place (700 billion dollars).

The concept of "creative industries" was first worked out in Great Britain in 1999. Today they account for $5.4 \%$ of the British economy, whereas the amount of profit in cultural and creative industry amounted to $6.2 \%$ of the GDP. They are a part of the global market of 2250 billion pounds, as well as one of the fastest growing sectors in the world and includes 13 sectors of cultural and economic activity. The results of official research confirm the fact that $49-69 \%$ of workforce in cultural and creative industries are highly qualified (i.e. have a degree). Cultural and creative industries are acknowledged to be a source for innovations, economic growth, personal wellbeing and social unity, but the use of their potential is made possible only by means of modern digital technologies.

In this way, the British Department for Culture, Media and Sport defined cultural and creative industry as "an activity based on individual creativity, skill or talent, which leads to the creation of tangible and intangible values, as well as new jobs through the production and exploitation of intellectual property" [4].

The analysis of the time series of import and export of cultural values in 2011-2016 at the state level reveals the trends from double digit growth to double digit fall (Figure 2). 17 member states of the EU reported positive growth in export. Poland, Latvia and Croatia had the highest growth of cultural export $(+24 \%,+11 \%$ and $+10 \%$ respectively) in 2011-2016. 


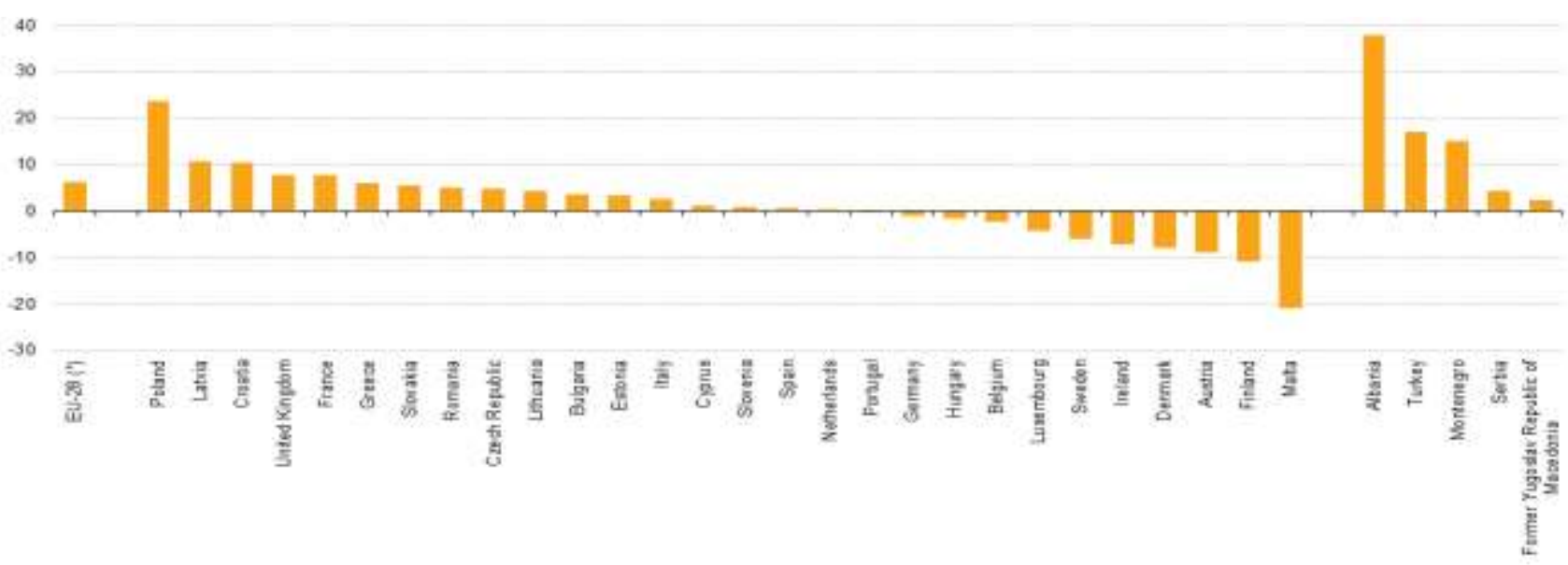

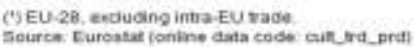

Fig. 2. Annual average growth rate of exports of cultural goods, 2011-16 (\%) (according to the Eurostat data).

In spite of the growth of cultural trade in 2011-2016, the export of cultural values outside the EU still accounts for a rather low percentage of the total export outside the EU (1.3\% in 2011 and $1.5 \%$ in 2016).

A decrease in import and export of cultural values can be caused by a number of factors. Economic environment, digital shift for a large number of mass media and challenges created by new technologies, undoubtedly, influence cultural consumption patterns and, as a result, the contents of the basket of imported and exported cultural goods.

\section{RESULTS AND DISCUSSION}

Public-private partnership in cultural industries presupposes organizational, legal and financial models recorded in official documents that ensure mutually beneficial interaction of public and private sectors of economy and culture. The application of such partnership in cultural industries is seen, first and foremost, as a mechanism of joint investment of resources in the realization of sociocultural projects, sharing risks, distributing costs and responsibility in course of the realization of such projects on the contract basis. Public involvement in socio-cultural projects can be accounted for by the necessity of stimulating innovational cultural processes which cannot be managed by the market environment.

A rapid development of cultural industries in 1980-1990s testifies changes in investment strategies in industrialized countries. We observe the global trend of the increase of investment in service industries; however, this shift is not characteristic of the Russian Federation. As the entertainment industries came to be perceived as the main sector of economy in North America and Europe, cultural industries came to be seen as a prestigious form of gaining profit [5]. Large companies from other sectors of economy made substantial investments in cultural production in 1980s. As for the Russian Federation, there are neither public, nor political structures or traditions that might successfully implement these new systems. A certain vacuum appears as far as interactions between the state, business and culture are concerned.

The research conducted by the European Cluster Observatory in 2013 elicits the conditions for the fulfillment of the necessary and sufficient requirements (the existence of historical, cultural and artistic heritage, the critical mass of the creative class and businessmen in the region, a developed educational and research environment, inter-disciplinary collaboration and the existence of physical and social space).

If the necessary and sufficient requirements are fulfilled, the supportive measures for the stages of the life cycle of the development of cultural and creative industries include:

- Financial guarantee schemes and other financial credit mechanisms, accessibility of seed and venture capital etc.;

- Production measures - the critical mass of the participants of the production chain of cultural and creative goods and services;

- Market measures - closeness to the consumer, marketing support;

- Educational measures - programmers of the development of creativity through the system of education, protection of the author's and neighboring rights;

- Administrative and political measures - support of creative start-ups, support of the mobility of artists and flexible labor markets, support of the international character of creative business;

- Support - strategy documents on the development of cultural and creative industries, formation of specialized creative clusters and integrated service centers of cultural and creative industries.

According to the government programmer of economic development (following the presidium session of the Russian State Council of 11.11.2011) and the decisions of the Government panel on high technologies and innovations of 
30.01.2012, the Russian Ministry of Economic Development, together with the federal executive authorities concerned, elaborated a project of pilot programmers for the development of territorial clusters that can be applied in cultural and creative industry. "An innovative territorial cluster" is defined as "the total of enterprises and organizations (participants of the cluster) situated within a certain territory, characterized by the presence of: the element uniting the participants of the cluster of scientific production chain in one or several sectors (key types of economic activity); the mechanism coordinating the activity and cooperation of the cluster participants; and a synergetic effect expressed in the increase in economic efficiency and effectiveness of the activity of each enterprise or organization due to a high level of their concentration and cooperation" [6].

Adopting the approach developed in European universities, a classification has been elaborated; according to it, the main clusters oriented towards regional needs for the Russian cultural industry may become the following ones: educational, public (social), museum and historical, and entertainment as in "Fig. 3".

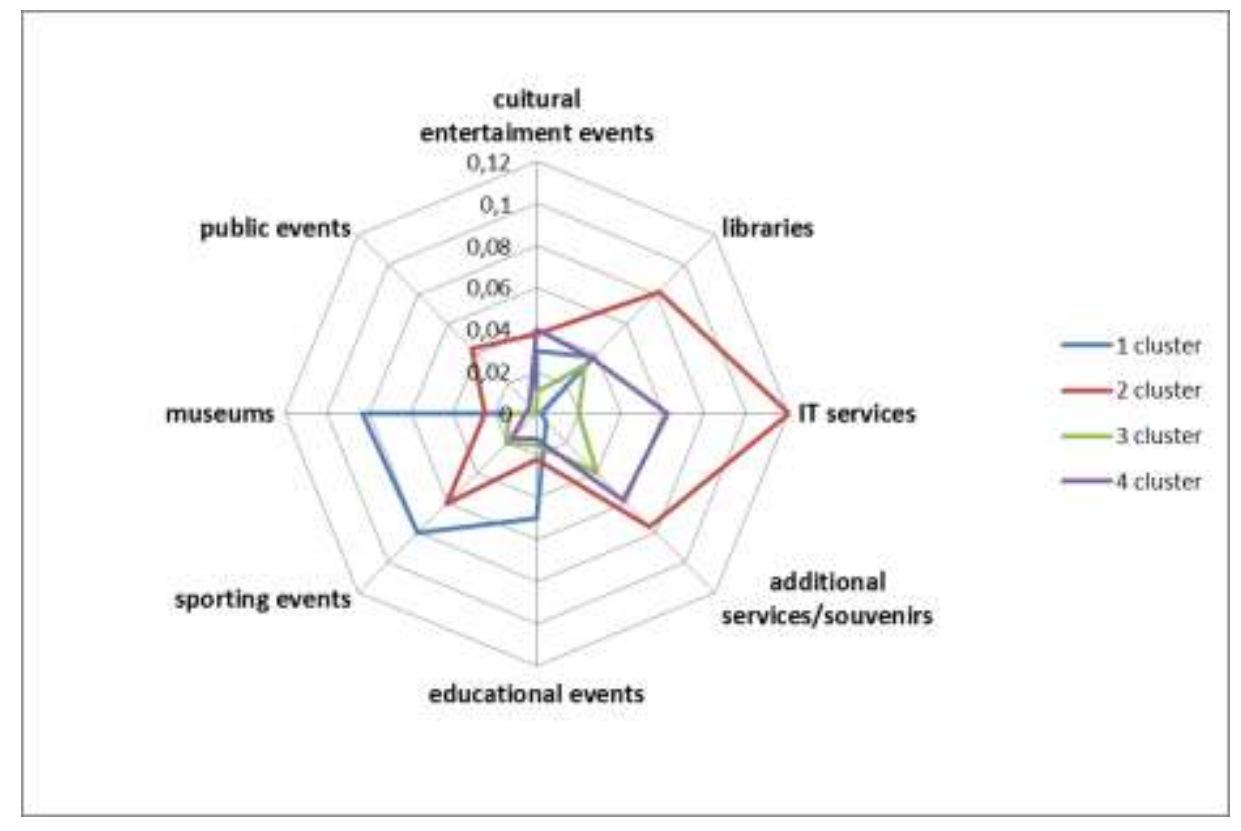

Fig. 3. Cluster classification of the subjects of cultural industry.

In different clusters the subjects of cultural industry can be oriented towards: interaction with business structures, educational technologies, regional demand for certain competences and skills of future specialists, organization and planning of the population's leisure time, and building a powerful cultural potential in the region.

In France the economic model of the support of cultural and creative industry is best reflected in the economic model based on the classification into groups of objects providing cultural and creative products in small and medium-size localities according to the repertoire, the focus group of customers and the type of support they receive (automatic and selective). The classification is grounded, first and foremost, on the analysis of the previous period of functioning in course of one or one and a half year. It is adjusted taking into account two weighting coefficients (the increase coefficient includes the total number of films in the repertoire of a cinema theatre, the activity of film clubs, socio-demographical situation in the region and competitive environment, whereas the reduction coefficient refers to the state of the showing room, the variety of films on the billboard, operating schedule (part-time or half-time), missed deadline for application, absence of club activity, cultural peculiarities of the respective region, efforts of the movie theatre in promoting films, and existing financial opportunities for conducting advertising campaigns). At the same time, small localities and big cities are considered separately, the minimum and maximum amount of subsidies are settled and only conscientious taxpayers are accepted the ones that provide a preliminary marketing study, control of purpose expenditure, clear criteria for the selection of movie theatres and amounts of grants that would be known and understood by all players on the market, while the procedure of selection is absolutely democratic (Source: CNCDossiers; results 2010-2014). This mechanism of support also allows to apply the cultural policy of supporting a certain range of services in cultural and creative industry to a separate actor in a pointed and directed way.

Apart from receiving strictly financial support, movie theatres can also count on the financial guarantee on part of the Institute for the Financing of Cinema and Cultural Industries (IFCIC) which can cover up to $50 \%$ of the required loan, if they comply with four criteria the total of which can give the maximum score: a difficult repertoire with a rare range of products; comfortable conditions; club activity (discussions, performances, social events etc.); balance between the range of activities and the financial situation. 
Applying the techniques of financing cultural and creative industry approved by the EU seems to be possible in Russia as well. When calculating increase and reduction coefficients, we have to create a model that would allow to form a mechanism based on organizational, behavioral and technical interconnections and work out measures of government policy for the realization of this form of financing cultural and creative sphere in today's economy.

The creation of an integrated regulation system of the control over financial processes should be carried out with the help of the economic-mathematical model of forming sustainable flow of services that would ensure high quality and adaptability of the services provided. The main features and characteristics of each criterion of the classification of the services provided by cultural and creative industry are expressed by means of weighting coefficients. The latter are assigned to each characteristic; in this way, an integrated index is further calculated.

The calculation of the criterion weight can be conducted using the method of expert evaluation, as well as the formal method of determining weighting coefficients. The most efficient method in the theory of expert evaluation has proved to be the ranking and scoring methods. In this case, weighting coefficients are determined as follows:

$$
\lambda_{i}=\frac{r_{i}}{\sum_{i=1}^{m} r_{i}}-(\mathrm{i}=1,2, \ldots, \mathrm{m}),
$$

- the formula for calculating weighting coefficients li using the ranking method.

Where L of experts assign figure 1 to the most important partial criterion, figure $2-$ to the next important partial criterion etc.

These ranks are transformed in such a way that rank 1 gets mark $m$ (the number of partial criteria), rank 2 gets mark $\mathrm{m}-1$ etc. until rank $\mathrm{m}$ which gets mark 1 . Let us designate the derived marks rik - where $\mathrm{i}$ is the number of the $\mathrm{i}$-th expert, and $\mathrm{k}$ is the number of the $\mathrm{k}$-th criterion.

$$
r_{i}=\sum_{j=1}^{L} r_{j i}, \mathrm{i}=1,2, \ldots, \mathrm{m},
$$

When using the scoring method, experts evaluate the importance of a partial criterion on the scale from 0 to 10 . Moreover, it is allowed to evaluate the importance of a partial criterion by fractional values and to assign the same value from the chosen scale to several criteria. Let hik designate the score of the i-th expert for the k-th criterion, then

$$
r_{i k}=\frac{h_{i k}}{\sum_{k=1}^{m} h_{i k}}
$$

where $\sum_{k=1}^{m} h_{i k}$ is the sum of the i-th line. rik is the weight calculated for the $\mathrm{k}$-th criterion by the ith expert. Therefore, taking into account that $r_{i}=\sum_{j=1}^{L} r_{j i}$, we arrive at

$$
\lambda_{i}=\frac{r_{i}}{\sum_{i=1}^{m} r_{i}}
$$

If the rates of an element change, they change for each element and for the whole system. Weighting coefficients change according to each structure component respectively.

At present, the structure of the sources of investment of socio-cultural projects in Russia brings about a disproportion between public and state sectors and an asymmetry between economic needs and possibilities of financing these projects. The need for the compensation for these imbalances defines the main objectives of public-private partnership in cultural sphere, and namely: effective distribution of limited resources in the cultural sphere; formation of new segments of cultural services market; development of infrastructure; considering specific needs of the subjects of the Russian Federation; decrease of private investors' risks; support of socio-cultural projects at the stage of development and implementation; aid to small and medium-sized businesses; and integration of cultural organizations, society and business.

The state as a part to the partnership agreement of the mechanism of public-private partnership can assume the functions of risk insurance by means of providing guarantees on state credits or subventions at different levels, export credit insurance and counter-guarantees [7].

\section{CONCLUSION}

The partnership of private and public sectors of economy has quite a few positive strategic characteristics as it contributes to greater efficiency of cultural activity and allows to successfully solve the issues of further commercialization of the results and the creation of a competitive environment by inviting open and transparent tenders in the realization of socio-cultural projects; taking into account the life cycle of projects, it also creates a basis for long-term contractual relationship in the field of formation and commercialization of cultural activity.

Applying the mechanism of public-private partnership to cultural activity creates an innovational business environment which contributes to attracting additional resources and joining the resources and potentials of the two business entities - state and business. That is the reason why the essence of the mechanism of public-state partnership is so similar to the mechanism of public-private partnership in innovational activity.

The main instruments of public-private partnership in cultural industries include legal, organizational and financial forms, whereas the models are methodological, organizational, resource, legal and motivational support. The directions of the use of public-private partnership are 
multilateral: governmental and political support, organizational-economical and investment-financial conditions, legislative basis and staffing.

As a result, the effectiveness of cultural industries increases by means of compensating for costs and sharing risks, along with long-term investment with an acceptable level of income and risk. Apart from direct effectiveness, the influence of culture on economic efficiency also has an indirect impact revealed in supporting the values common for customer groups which define the ways of involvement of the members of a group into economic production processes. Thus, cultural values bring innovation, effective administrative decision-making and adapted organizational behaviour, which reflect themselves in high financial results of activities and growth rates of economic indicators.

The conducted analysis provides ground for the conclusion concerning the necessity of the development of cultural industries by means of implementing the mechanism of public-private partnership, balanced in terms of the correlation between risks and responsibility. This mechanism will allow to reduce costs, ensure investment and lower the risk level in the cultural industry, thus determining its attractiveness and competitiveness.

\section{REFERENCES}

[1] D. Hezmondalsh, Culture / transl. from English. I. Kushnareva; under the science. A. Mikhalev (ed.) ; NAT. Research. University Higher School of Economics. M.: Publishing House of Higher School of Economics, 2014, p. 81.

[2] P. Bourbieu, The Field of cultural production: essays on art and literature/ R. Jonson. Cambridge: Polity press, 1993, p. 21.

[3] D. Trosbi, The economy and culture. M..: Publishing House of Higher School of Economics, 2013, p.159.

[4] Creative Britain: New Talents for the New Economy, DCMS/BERR/DIUS(2008), London

[5] M. J. Wolf, The entertainment economy, L: Penguin. 1999, p. 34.

[6] The Ministry of economic development of Russia, URL: http://economy.gov.ru/minec/main

[7] Yu Vygodchikova et al., Estimation of Bond Risks using Minimax, Journal of Advanced Research in Law and Economics, 2017, vol. 7, pp. 1899-1907. 